\title{
Failure in a pipe due to defective maintenance
}

\section{Falla de tubería por deficiencias en mantenimiento}

\author{
SALGADO-LÓPEZ, Juan Manuel†*, OJEDA-ELIZARRARAS, José Luis, LOPEZ-MONROY, \\ Francisco Ignacio and TELLO-RICO, Mauricio
}

CIDESI, Materials Technology, Metallography Laboratory and Failure Analysis. Mexico.

CIDESI, Joining Technologies, Welding Laboratory, Mexico.

ID $1^{\text {st }}$ Author: Juan Manuel, Salgado-Lopez / ORC ID: 0000-0002-2384-1887, CVU CONACYT ID: 94744

ID $1^{\text {st }}$ Co-author: José Luis, Ojeda-Elizarrarás / ORC ID: 0000-0001-8412-7778, CVU CONACYT ID: 81630

ID $2^{\text {nd }}$ Co-author: Abraham, Silva-Hernandez / ORC ID: 0000-0003-2699-8107, CVU CONACYT ID: 726099

ID $3^{\text {rd }}$ Co-author: Jesús Mauricio, Tello-Rico / ORC ID: 0000-0002-5657-2134, CVU CONACYT ID: 586320

DOI: $10.35429 / J M E .2021 .15 .5 .1 .7$

Received January 10, 2021; Accepted June 30, 2021

\begin{abstract}
Proper maintenance of energy transport pipelines is a part of energy efficiency since energy losses during transport are reduced with good maintenance practices as well as the mechanical integrity can be known. Moreover, it reduces the risk of accidents or environmental damage. This work is an example of the experiences that must be taken into account for optimal pipeline maintenance and consisted of a failure analysis performed on a 20 -inch diameter " $\mathrm{T}$ " connection, which plays an important role in the energy transportation process and it was found to be partially buried with exposure to rainwater. Preventive maintenance consists of visual inspection, cleaning, and coating with paint. The results indicated that the failure begun due to fatigue with origin in weld defects and the fracture grew up due to an overload, which caused the crack to grow following the region of the material with loss of thickness induced by corrosion pitting.
\end{abstract}

\begin{abstract}
Resumen
El mantenimiento adecuado de los ductos para transporte de energéticos es parte de la eficiencia energética, ya que así se logran reducir las pérdidas durante el transporte y se puede conocer la integridad mecánica de estos y con ello reducir el riesgo de accidentes o daños ambientales. Este trabajo es un ejemplo de las experiencias que deben ser tomadas en cuenta para un mantenimiento óptimo de los ductos y consistió de un análisis de falla realizado en una conexión tipo "T" de 20 pulgadas de diámetro, la cual tiene un papel importante en el proceso de transporte de energéticos y que se encontraba enterrado parcialmente con exposición al agua pluvial. El mantenimiento preventivo consistía de inspección visual, limpieza y recubrimiento con pintura. Los resultados indican que la falla ocurrió por fatiga iniciada en defectos de soldadura y la fractura termino por una sobrecarga que dio lugar a que la grieta creciera siguiendo la región del material con pérdida de espesor inducida por picaduras por corrosión.
\end{abstract}

Falla, Corrosión, Mantenimiento

Citation: SALGADO-LÓPEZ, Juan Manuel, OJEDA-ELIZARRARAS, José Luis, LOPEZ-MONROY, Francisco Ignacio and TELLO-RICO, Mauricio. Failure in a pipe due to defective maintenance. Journal of Mechanical Engineering. 2021. 5$15: 1-7$.

\footnotetext{
* Correspondence to the Author (Email: msalgado@ cidesi.edu.mx)

$\uparrow$ Researcher contributing as first author.
} 


\section{Introduction}

Preventive maintenance is crucial for wellfunctioning of industry and to avoid accidents.

This is especially true for energy industry because there are risks of accidents or leaks, which jeopardizes the health of people and the environment Nevertheless, in some cases preventive maintenance consists only on external cleaning. This bad practice leads to consequences as the shown in this work.

Loss of productivity due to unplanned maintenance or repairs are some of the mild consequences of such shallow maintenance. Besides temporary repairs require additional work for their final correction, or in the worst case, they fail before being corrected. All of this commonly leads to a worst situation.

When a failure occurs, which affects production, the quality of the products, the safety of people or that might cause a serious environmental impact; it is essential to carry out a failure analysis to determine the metallurgical cause that led to the failure. From the conclusions of the analysis, real actions can be undertaken in order to prevent such events from occurring again. Failure analysis, it is linked to the criticality of the energy production or transport equipment to prioritize preventive maintenance activities and their planning; since maintenance requires studying the incidents that happened and providing real solutions to avoid them.

This work consisted of a failure analysis performed on a 20-inch diameter " $T$ " type connection, which plays an important role in the energy transport process. The objective of this work was to determine the metallurgical mechanism, which led to the fracture of this component and with this work it is shown that a poor practice in preventive maintenance leads to process failures and unplanned stoppages.

\section{Methodology}

The construction of this "T" type connection dated from 1980 and the material was ASTM A 53 grade $\mathrm{B}$ steel. This component was approximately 2.30 meters long, 500 millimeters in diameter and approximately 7.85 millimeters thickness.
It should be mentioned that the thickness was not constant since the specimen under study showed red oxidation on both sides; the "T" connection was 500 millimeters in diameter, in addition to a 300 millimeters of diameter hole. There was a primary crack that began transversely to the radius of the tube and then towards a semicircle of approximately 50 centimeters long whose possible origin was detected in the joint weld of the " $\mathrm{T}$ " with the tube. This is shown in figure 1 .

In order to achieve the aim of this work, the following techniques were applied: visual inspection with the naked eye and using Leica brand stereographic microscope, this technique was carried out to demonstrate the circumstance of delivery to the laboratory of the specimen under study and determine the origin of the fracture if there is significant macroscopic evidence.

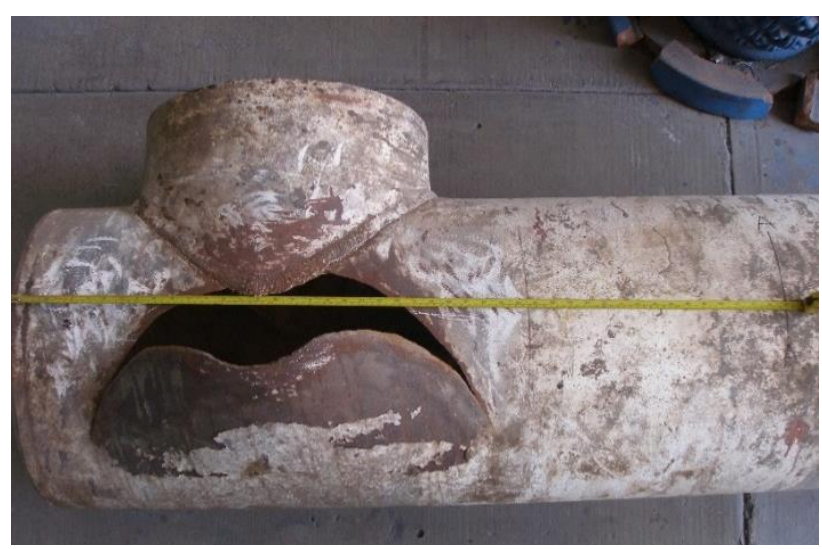

Figure 1 The image the connection type "T" in the condition of delivery to the laboratory. Note the fracture and coating on the external surface

Source: Own work

The thickness measurement was done by means of the ultrasonic testing with a straight beam receiver using a GE equipment model USM / DMS Go, this non-destructive testing was necessary in order to be able to determine the areas of the " $T$ " connection with reduction in thickness.

To find damage in the microstructure of this component steel, a microstructural analysis was carried out using a Nikon Epiphot 440 brand metallographic optical microscope. The samples were taken by transversal mechanical cuts. These samples were mounted on Bakelite, grinded and polished using sandpaper from 120 to 2000. After that these samples were polished using 1 micron particle size alumina powder and subsequently etched with nital 2 to reveal the microstructure.

SALGADO-LÓPEZ, Juan Manuel, OJEDAELIZARRARAS, José Luis, LOPEZ-MONROY, Francisco Ignacio and TELLO-RICO, Mauricio. Failure in a pipe due to defective maintenance. Journal of Mechanical Engineering. 2021 
Finally, the fracture pattern of the failed " $T$ " connection was observed by a Phillips Model XL-30 scanning electron microscope (SEM) and EDS elemental microanalysis with EDAX.

\section{Results}

Visual testing on the " $T$ " type connection showed that the pattern of the crack at the ends was ductile and that the origin was located in the weld toe of the " $T$ " connection (figure 2). From this fact it can be deduced that the origin of the crack was located at the weld toe and that the fracture was initiated by some defect in it.

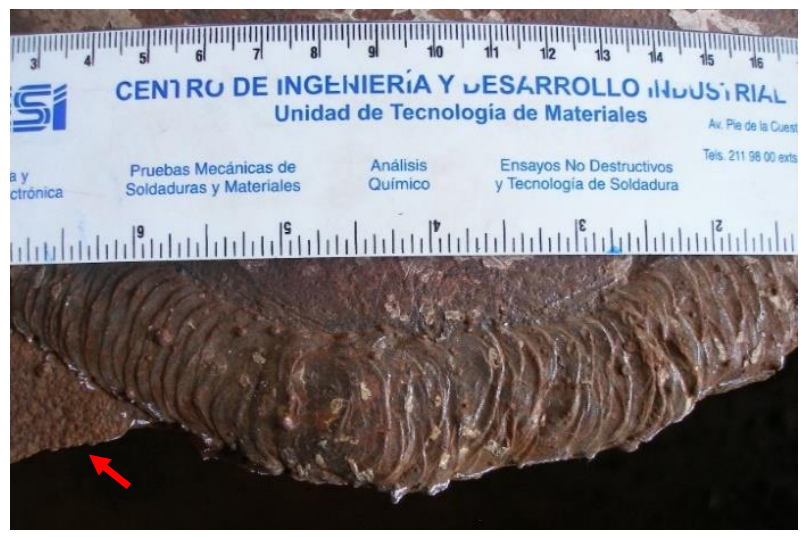

Figure 2 The image shows the fracture zone in the region of the weld

Source: Own work

Moreover, it should be mentioned that by this technique, corrosion pitting was found in the area near the crack (figure 3). Figure 3 shows that the crack grew following the regions of the material with reduction in thickness due to corrosion, since the crack changed its path respecting to the origin located at the weld toe.

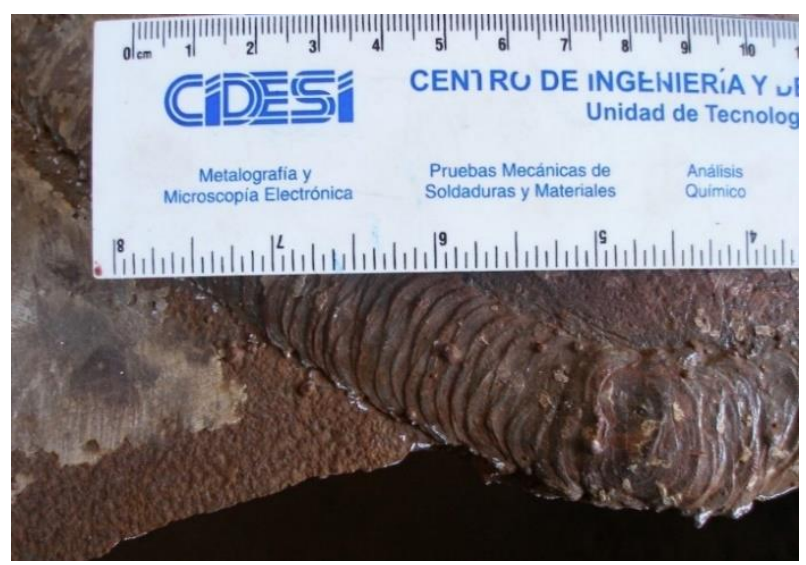

Figure 3 The image shows the right area of the crack. There is seen the change in crack growth from the weld toe to the body of the pipe

Source: Own work
Visual testing of the fracture surface showed an incomplete fusion and a layer of red corrosion products. This evidence is shown in Figures 4 . With this evidence it is verified that the welding defects played a role in the crack growth of this component.

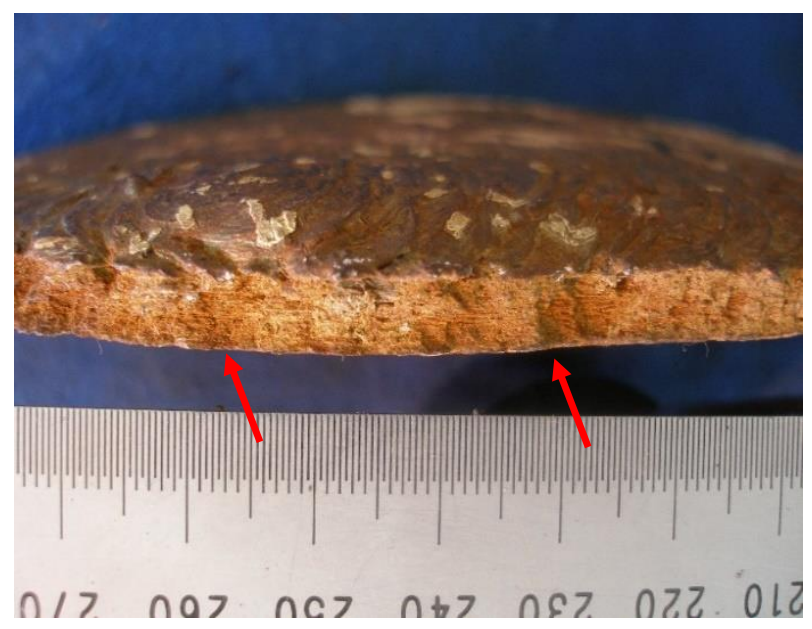

Figure 4 The image shows the fracture surface. The fracture surface is covered with a layer of red corrosion products and there is seen a lack of fusion Source: Own work

In the same way, visual testing also revealed the existence of red corrosion products inside the "T" connection, which indicates that there was oxygen corrosion in this part of the component. This resulted in a loss of thickness. Figure 5 shows evidence of corrosion pitting inside the "T" connection.

On the other hand, the thickness measurement carried out on the connection type " $\mathrm{T}$ " revealed that there is only a slight reduction in thickness in the area of the fracture with respect to the main tube of the connection " $\mathrm{T}$ ". This is shown in tables 1 and 2 .

Figure 6 shows the regions where the thicknesses were measured with the straight beam ultrasonic testing. 


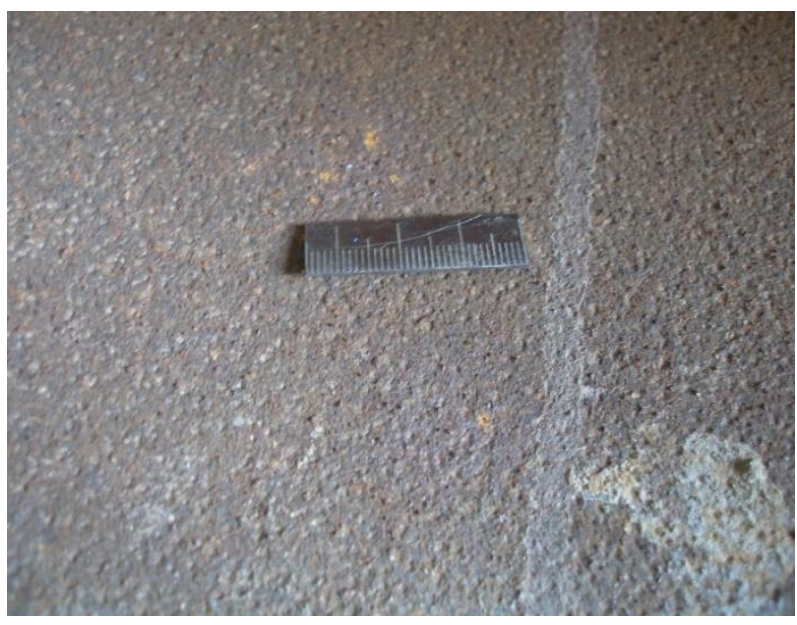

Figure 5 The image shows corrosion pitting inside the tube. (The layer of red corrosion products was removed from the surface)

Source: Own work

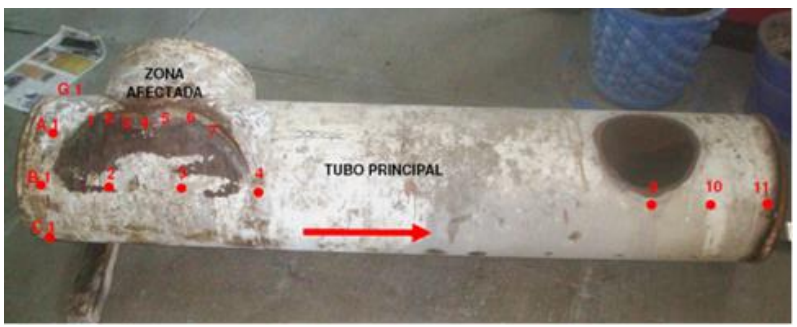

Figure 6 The image shows the regions where the thicknesses measurements were carried out

Source: Own work

From Tables 1 and 2 it can be noted that the maximum thickness of the main tube was 5.92 millimeters; while the minimum thickness detected was 5.31 millimeters and this was in the pitted area (close to the fracture surface). Perhaps this data does not seem relevant but if this reduction in thickness in this area of "T" the component is combined with the welding defects found by visual inspection, we can deduce that the stress applied by the internal pressure of the tube in this region of the connection was more higher than in other regions of the same specimen.

\begin{tabular}{|l|r|r|r|r|r|r|r|}
\hline \multicolumn{7}{|c|}{ Measurement points in the HAZ } \\
\hline & 1 & 2 & 3 & 4 & 5 & 6 & 7 \\
\hline A & 5.41 & 5.44 & 5.53 & 5.64 & 5.59 & 5.31 & 5.36 \\
\hline
\end{tabular}

Table 1 Results of thickness measurements in the HAZ Source: Own work

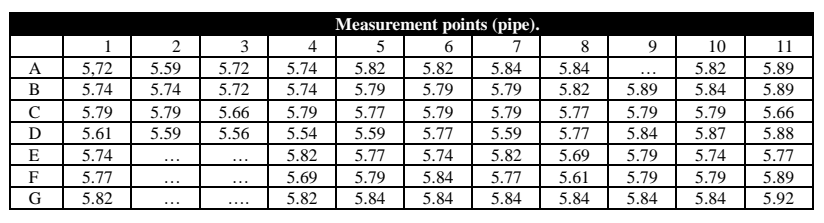

Table 2 Results of thickness measurements along the " $T$ " connection

Source: Own work
The metallographic analysis carried out in different regions of the "T" connection showed evidence that defects such as: trapped slag or lack of fusion, which serve as stress risers. This is shown in figure 7.

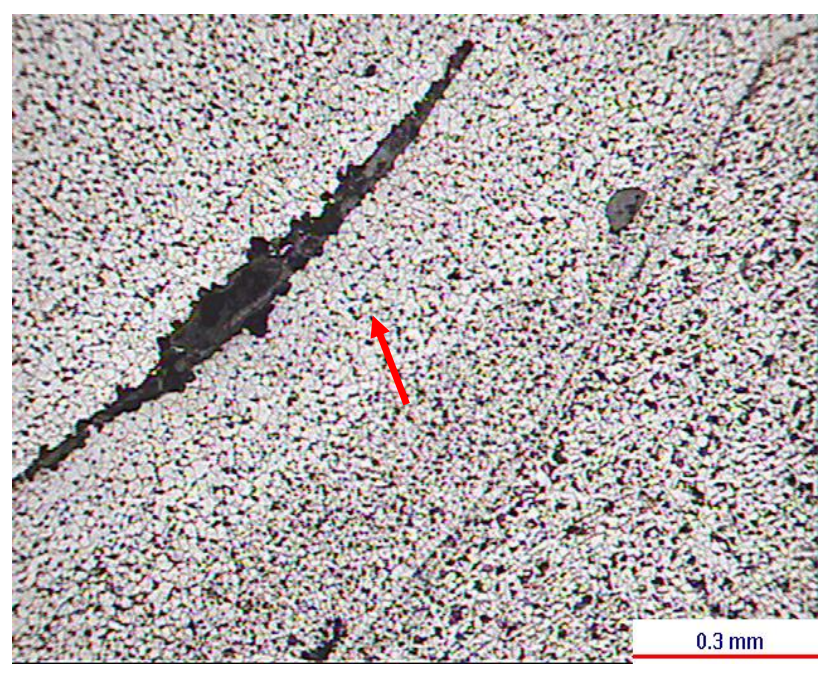

Figure 7 Microstructure of the welded joint. Incomplete fusion is observed

Source: Own work

Similarly, the cross-sectional micrograph at the weld joint showed evidence of a fold on the outside of the weld. This can be seen in Figure 8. Besides, metallographic analysis confirmed the presence of corrosion pitting within the tube material of the " $\mathrm{T}$ " connection in the fracture region of the specimen. This fact is very important since corrosion pitting is a very severe form of damage; because the bites act as stress concentrators. This can be seen in figure 9 .

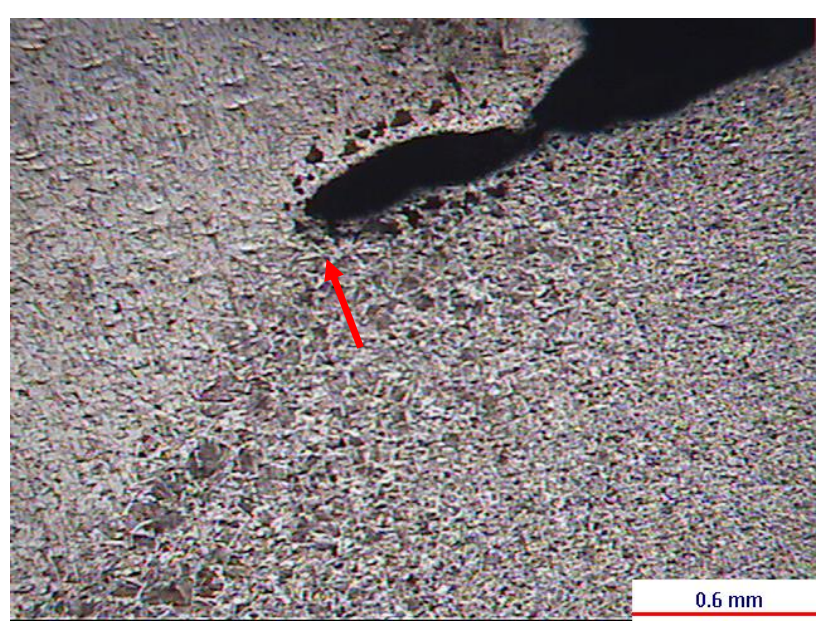

Figure 8 Microstructure in the fold of weld Source: Own work

Figure 10 shows the microstructure in a cross section to the fracture surface of the "T" connection, there is evidence of corrosion pitting and a secondary crack that grows from the pit. 


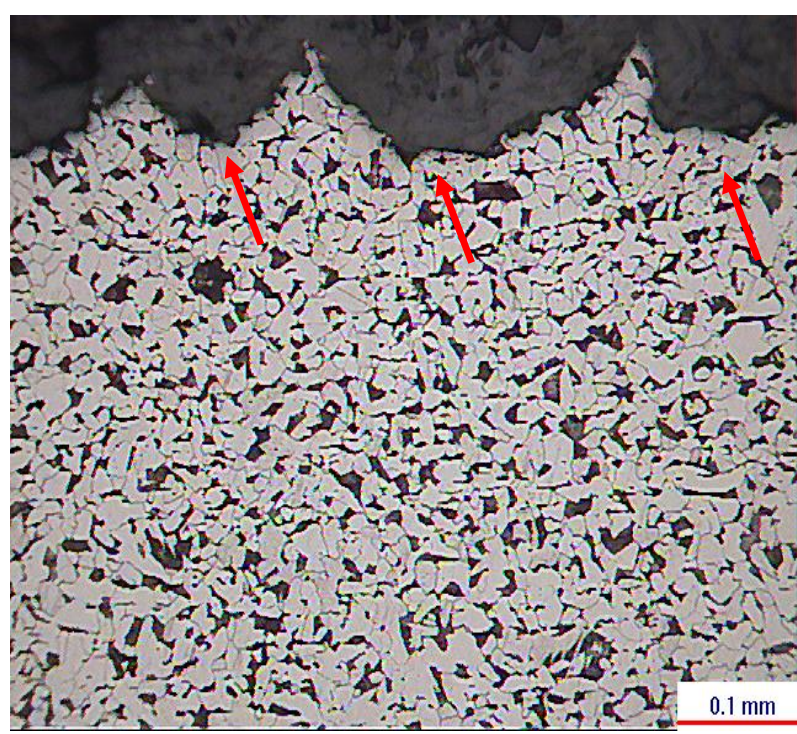

Figure 9 Micrograph at 200x. There is seen the microstructure of the base material and pitting on the outer surface of the base material

Source: Own work

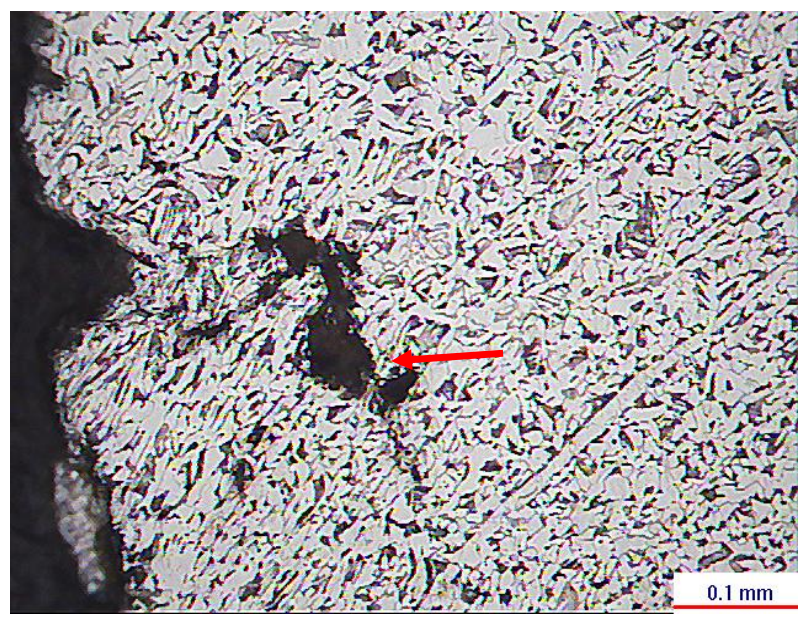

Figure 10 Micrograph at 200x. Microstructure near the crack

Source: Own work

The fractographic analysis showed beach marks near the origin of the crack. This means that the crack growth occurred due to fatigue (figure 11). However, it should be mentioned that the corrosion degraded the evidence. Furthermore, weld defects such as incomplete fusion and porosity were found in this region of the fracture. This fact shows that these defects are stress risers where fatigue cracks begun. This matches with the fact that this component works in compression cycles during oil / decompression transport.

On the other hand, in the area of the crack where it grew away from the weld toe, a wooden pattern was observed (figure 12). This pattern is the mixture between a cleavage and dimples.
This fact indicates that the crack grew from welding defects due to the fatigue mechanism and then it finished cracking due to an overload.

This overload was conjunction of the work stress of the connection acting in the region of the pipe with thickness reduction. This region that had to withstand the work effort was reduced in mechanical strength due to the reduction in thickness caused by corrosion pitting.

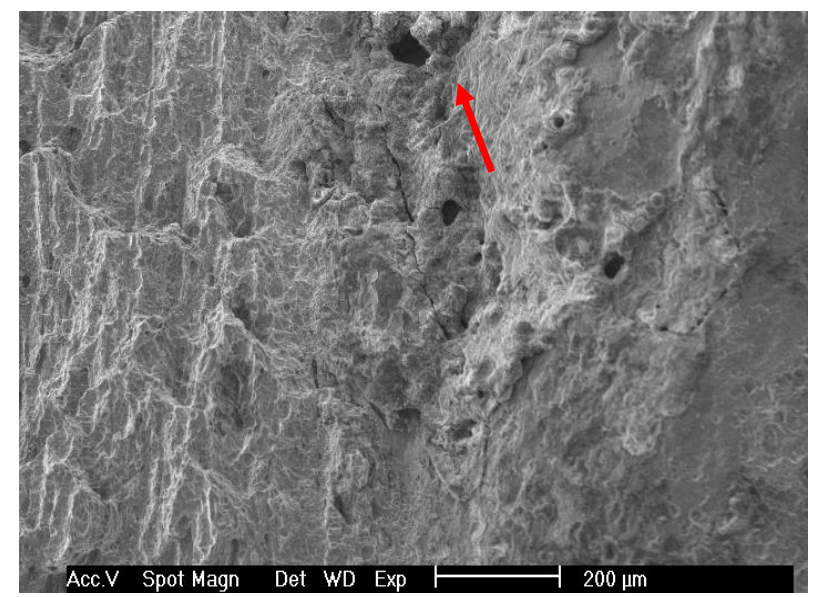

Figure 11 Fracture surface in the partial fusion zone. Incomplete fusion, porosity cavities and secondary cracks are observed

Source: Own work

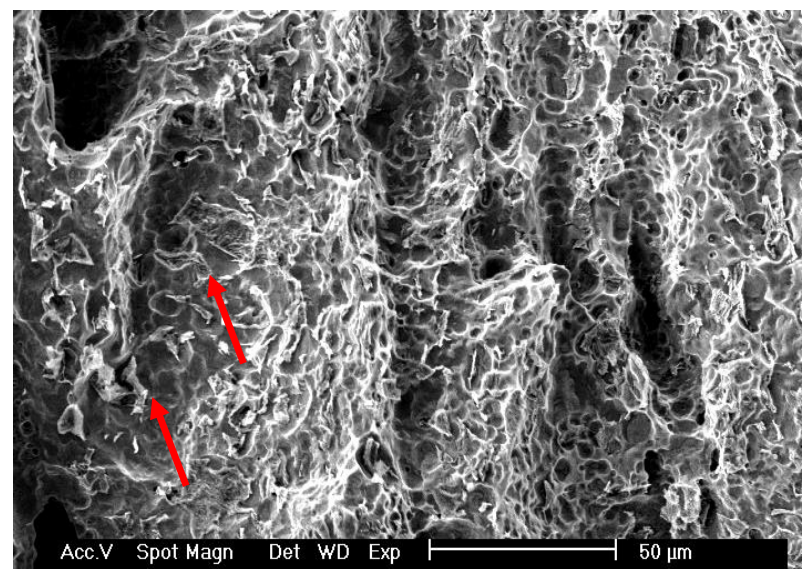

Figure 12 Fracture surface at the crack tip away from the welded joint. The image shows cleavage and dimples Source: Own work

\section{Discussion}

Considering the above mentioned results, it can be said that the 20-inch diameter " $T$ " type connection failed due to the metallurgical mechanism known as fatigue. This damage started due to defects in weld and the crack grew catastrophically due to an overload. It acted in the region with thickness reduction due to corrosion pitting. 
One has to consider that the failure of this component occurred despite preventive maintenance, which consisted of visual inspection and painting; then it can be deduced that this was not a good maintenance practice.

Then, from the evidence previously shown and discussed it is clear that at the beginning the crack grew by fatigue due to pressure/decompression cycles with origin in weld defects such as incomplete penetration. These types of welding defects are detected by non-destructive tests, this is also valid for the growth of the crack and the loss of thickness in the HAZ. Besides, the results of non-destructive testing can be used to feed a methodology of mechanical integrity, with which it is possible to give predictions of the growth of corrosion damage and thus design strategies for the replacement of said component.

Finally, combining the previously discussed evidences with the defective practice maintenance mentioned it can be deduced that good preventive maintenance practices could avoid the catastrophic failure of this component.

\section{Acknowledgements}

The authors wish to thank the CIDESI Metallography and Failure Analysis Laboratory for their support in carrying out this work.

\section{Conclusions}

The "T" type connection failed due to fatigue, which started in defects in the HAZ and the fracture grew catastrophically due to an overload acting in the region with a decrease in thickness due to corrosion pitting.

Weld defects act as crack initiators in equipment that is subjected to loading / unloading cycles and corrosion decreases the thickness of the material, causing cracks to grow in these places.

The evidence previously discussed shows that good preventive maintenance practices could prevent the catastrophic failure of this type of components.

\section{References}

Babu, S. K., \& Natarajan, S. (2008). Influence of heat input on high temperature weldment corrosion in submerged arc welded power plant carbon steel. Materials \& Design, 29(5), 10361042.

Barsom, J. M., \& Pellegrino Jr, J. V. (2002). Failure analysis of welded steel momentresisting frame connections. Journal of materials in civil engineering, 14(1), 24-34.

Bilmes, P. D., Llorente, C. L., Méndez, C. M., \& Gervasi, C. A. (2009). Microstructure, heat treatment and pitting corrosion of $13 \mathrm{CrNiMo}$ plate and weld metals. Corrosion Science, 51(4), 876-881.

Chaves, I. A., \& Melchers, R. E. (2011). Pitting corrosion in pipeline steel weld zones. Corrosion Science, 53(12), 4026-4032.

Cheng, B., Ye, X., Cao, X., Mbako, D. D., \& Cao, Y. (2017). Experimental study on fatigue failure of rib-to-deck welded connections in orthotropic steel bridge decks. International Journal of Fatigue, 103, 157-167.

Davis, J. R. (Ed.). (2006). Corrosion of weldments. ASM international.

Lu, Y., Jing, H., Han, Y., \& Xu, L. (2016). Effect of welding heat input on the corrosion resistance of carbon steel weld metal. Journal of Materials Engineering and Performance, 25(2), 565-576.

Mashiri, F. R., Zhao, X. L., \& Grundy, P. (2004). Stress concentration factors and fatigue failure of welded T-connections in circular hollow sections under in-plane bending. International Journal of Structural Stability and Dynamics, 4(03), 403-422.

Mellor, B. G., Rainey, R. C. T., \& Kirk, N. E. (1999). The static strength of end and T fillet weld connections. Materials \& design, 20(4), 193-205.

Mohammadi, F., Eliyan, F. F., \& Alfantazi, A. (2012). Corrosion of simulated weld HAZ of API X-80 pipeline steel. Corrosion science, 63, 323-333. 
Oosterhof, S. A., \& Driver, R. G. (2011). Effects of connection geometry on block shear failure of welded lap plate connections. Journal of Constructional Steel Research, 67(3), 525-532. Peköz, T., \& McGuire, W. (1979). Welding of sheet steel.

Shirinzadeh-Dastgiri, M., Mohammadi, J., Behnamian, Y., Eghlimi, A., \& Mostafaei, A. (2015). Metallurgical investigations and corrosion behavior of failed weld joint in AISI 1518 low carbon steel pipeline. Engineering Failure Analysis, 53, 78-96.

Xing, S., Dong, P., \& Threstha, A. (2016). Analysis of fatigue failure mode transition in load-carrying fillet-welded connections. Marine Structures, 46, 102-126. 